\title{
Technological Mineralogy of a Refractory Gold Ores
}

Shengchun Shi, ${ }^{1, a}$, Bo Yang ${ }^{2, b}$, Xian Xie ${ }^{2, c, *}$, Meicun Zhou ${ }^{1, d}$, Jianming Xue $\mathrm{e}^{1, \mathrm{e}}$

${ }^{1}$ Oxbridge College, Kunming University of Science and Technology, Kunming 650106, China

${ }^{2}$ Faculty of Land Resource Engineering, Kunming University of Science and Technology, Kunming 650093, China

a419714078@ qq.com,,boyang2012@sohu.com, '89235376@qq.com, d2212733340@qq.com, e913886788@qq.com

${ }^{*}$ Corresponding author

Keywords: Technological mineralogy; Refractory gold; Recovery.

Abstract. Technological mineralogy of a refractory gold ores from Gansu Province China was investigated by XRD, SEM and polarizing microscope, the results indicate that gold in ores exists mostly in sulfide minerals such as pyrite, arsenopyrite and stibnite, partly existed in gangue minerals such quartz and calcite. The final result is helpful for the recovery of gold.

\section{Introduction}

In recent years, with the depletion of gold deposits, gold ores resource that easy to leaching and exploration become increasingly scarce, and refractory gold ore have become primary stock for the production of gold. In addition, problems can occur when leaching gold using cyanide solution from refractory gold ores, such as these gold ores containing copper or carbonaceous minerals, will result in poor overall recovery of gold and high consumption of cyanide. Therefore, before leaching, a detail investigation of mineralogy is necessary for the recovery of gold effectively. The mineral composition of ores and occurrence state of gold were obvious through technological mineralogical research. In this thesis, technological mineralogy of a refractory gold ores were investigated by SEM-EDS and XRD.

\section{Experimental sample}

A refractory gold ore was obtained from Gansu Province, China, without any further treatment. Occurrence state of natural gold in raw ore was investigated by SEM coupled with EDS and polarizing microscope. The content of gold and other elements in ores and leaching residue were analyzed by AAS or chemical analysis. The gold ore was prepared for the analysis of technological mineralogy and leaching experiments. The processing flowsheet is shown at Fig.1

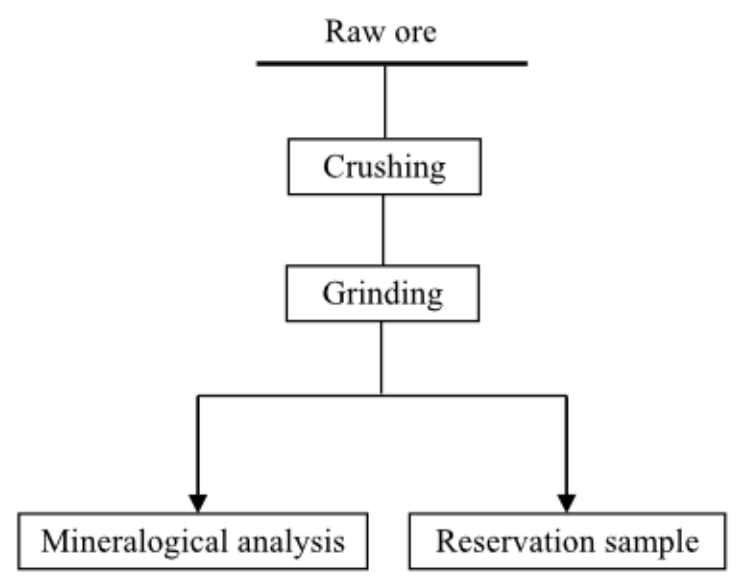

Fig.1 The preparation and leaching flow sheet of gold ore 


\section{Results and discussion}

The main elements and mineral composition of raw ore are shown in Table 1 and Fig.1: Table 1 Main chemical composition of raw ore (mass fraction. \%)

\begin{tabular}{cccccccccc}
\hline $\mathrm{Au}^{*}$ & $\mathrm{Ag}^{*}$ & $\mathrm{Sb}$ & $\mathrm{S}$ & $\mathrm{As}$ & $\mathrm{C}$ & $\mathrm{Fe}$ & $\mathrm{CaO}$ & $\mathrm{SiO}_{2}$ & $\mathrm{Al}_{2} \mathrm{O}_{3}$ \\
\hline 4.3 & $<5$ & 0.45 & 0.89 & 0.31 & 2.18 & 4.07 & 6.22 & 56.62 & 13.22 \\
\hline
\end{tabular}

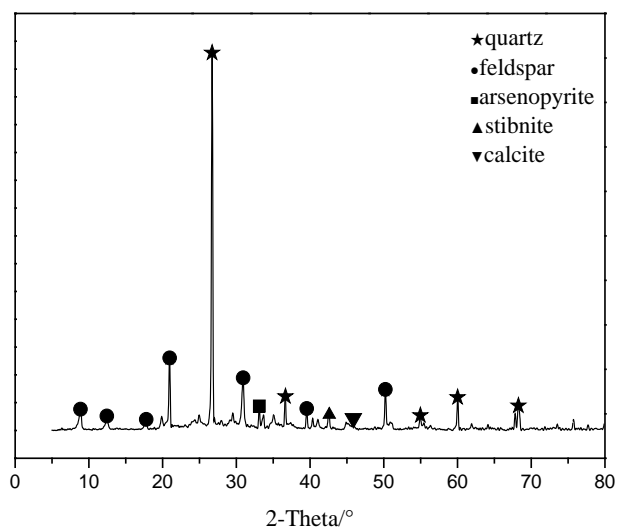

Fig.1 XRD pattern of raw ore

Table 1 shows that the main valuable elements in raw ore are Au and Sb, grade $4.3 \mathrm{~g} / \mathrm{t}$ and $0.45 \%$ respectively. Fig. 1 indicates that the main minerals in raw ores are quartz, feldspar, arsenopyrite and calcite, the content of quartz in ore is abundant relatively with other minerals.

The SEM images of main minerals in raw ore were shown in Fig.2, Fig.3, Fig.4 and Fig.5.

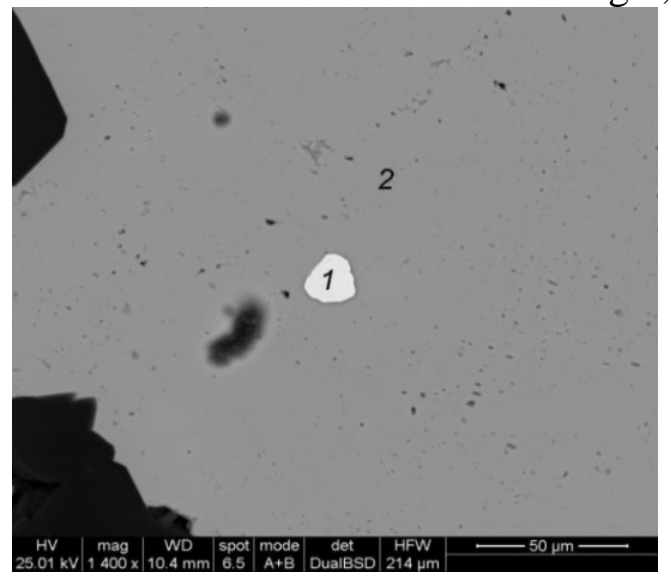

Fig.2 SEM images of gold disseminated in stibnite(1-gold,2- stibnite)

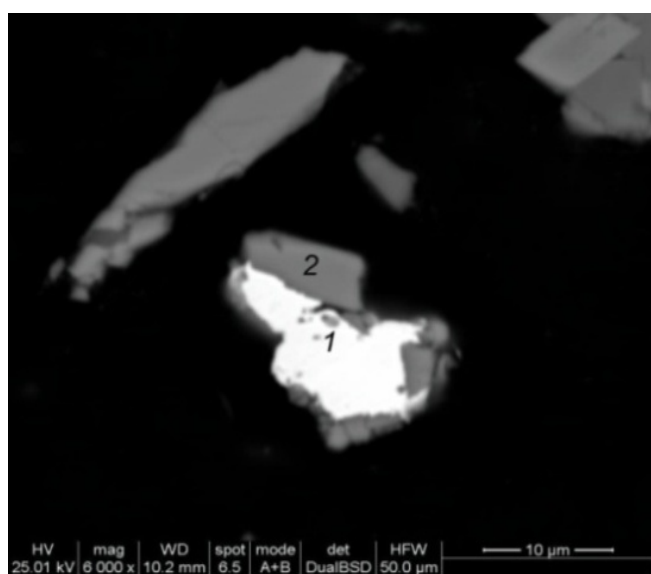

Fig.3 SEM images of gold disseminated in arsenopyrite cracks(1- gold,2-arsenopyrite) 


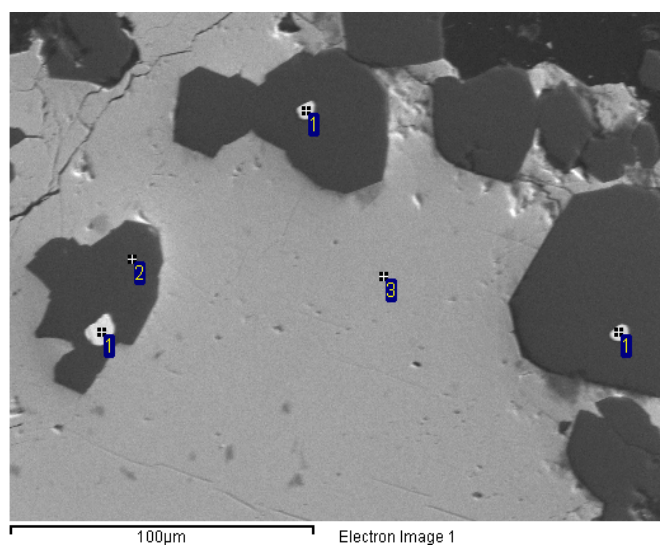

Fig.4 SEM images of gold disseminated in quartz(1-gold,2-quartz)

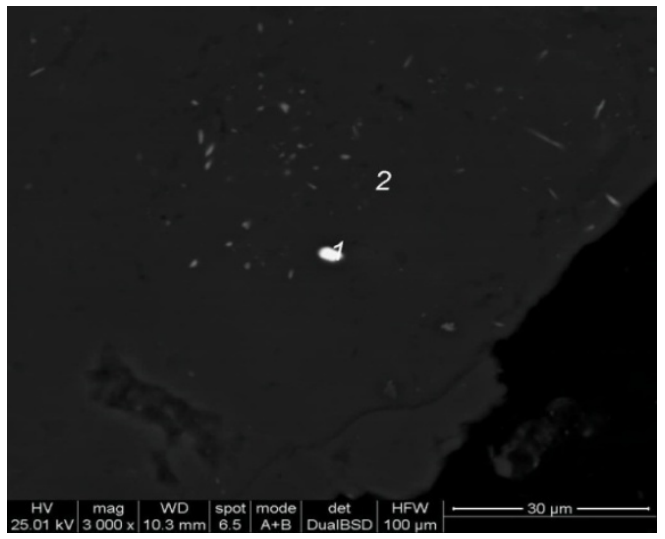

Fig.5 SEM images of gold disseminatedin calcite(1-gold,2-calcite)

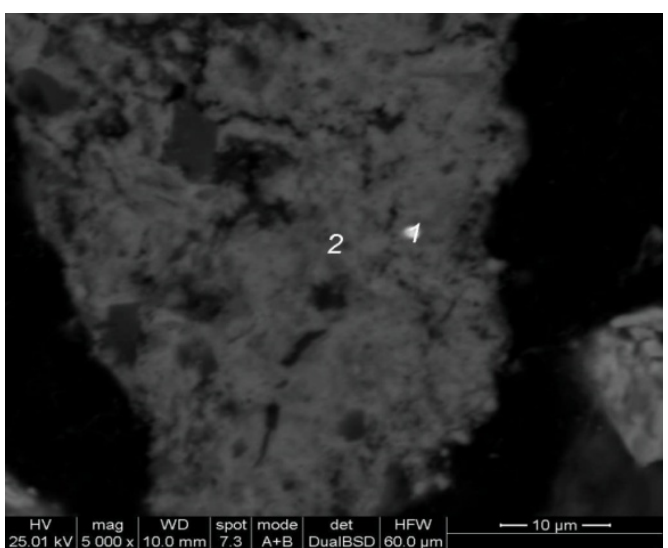

Fig.6 SEM images of gold disseminatedin oxide iron (1-gold,2-oxide iron)

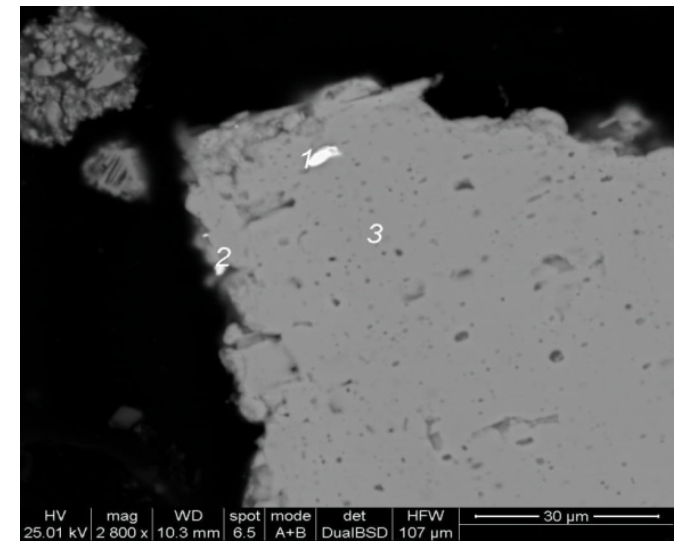

Fig.7 SEM images of gold disseminatedintetrahedrite (1,2-gold,3-tetrahedrite) 
As shown in Fig.2, Fig.3, Fig.4, Fig.5, Fig.6 and Fig.7, natural gold in raw ores mostly was locked in sulphide minerals such as stibnite, arsenopyrite and tetrahedrite, and gangue minerals such as quartz and calcite. Therefore, we can infer that the recovery of gold will be very poor if without any pre-treatment. On the other hand, if recovery gold through flotation beneficiation, recovery rate of gold will be poor due to the gold disseminated in quartz and calcite cannot be recovery. Besides, if leaching gold through cyanide solution, arsenopyrite and stibnite existed in raw ores will hinder the leaching of gold from ores effectively, and cause the consumption and oxidation of cyanide, passivation of leaching.

\section{Conclusions}

The research results indicate that gold in this refractory ores mostly existed in tibnite, arsenopyrite and tetrahedrite, partly existed in gangue minerals such as uartz and calcite. Through technological mineralogy research, we can infer that a ideal recovery of gold cannot be obtained by alone leaching techniques or beneficiation techniques. Therefore, in order to recovery gold from this refractory gold ores, pre-treatment or multi-step extraction techniques is necessary.

\section{References}

[1] Shang He, Wen Jiankuang, Wu Biao, et al. Bio-pretreatment and cyanide leaching for arsenic carbonaceous refractory gold ores[J]. Chinese Journal of Rare Metals, 2012, 36(6): 947-952.(In Chinese)

[2] Li Junmeng. Current situations of refractory gold ore's pretreatment method research and its tendency[J]. Chinese Journal of Real Meatal, 2003, 7(4): 478. (In Chinese)

[3] P.L Breuer, X.Dai, M.I. Jeffrey. Leaching of gold and copper minerals in cyanide deficient copper solution[J]. Hydrometallurgy, 78(2005): 156-165.

[4] Li Feng, Ding De-xin, Hu Nan, et al. Roasting oxidation-thiosulphate leaching of gold from refractory gold-bearing sulfur concentrates[J]. The Chinese Journal of Nonferrous Metals, 2004, 24(3): 831-836. (In Chinese)

[5] D. Feng, J.S.J. van Deventer. The role of oxygen in thiosulphate leaching of gold[J]. Hydrometallurgy, 2007(85): 193-202.

[6] Shen Zhihui, Zhang Qin, Mao Song, et al. Leaching of micro-disseminated gold ore deposit in Guizhou by thiosulphate, Mining and Metallurgical Engineering, 2013, 33(5): 85-90. (In Chinese)

[7] Zhou Li, Wen Shuming, Li Huawei. Pre-treatment technology and application of refractory gold ores[J]. Metallic Ore Dressing Abroad, 2004(3): 11-15. (In Chinese)

[8] D. Feng, J.S.J. van Deventer. The effect of sulphur species on thiosulphate leaching of gold[J]. Minerals Engineering, 2007(20): 273-281.

[9] Andrew C. Grosse, Greg W. Dicinoski, Matthew J. Shaw et al. Leaching and recovery of gold using ammoniacal thiosulphate leaching liquors[J]. Hydrometallurgy, 2003(69): 1-21. 